\title{
A pharmacoepidemiology study of local fungal infections in skin and venereal diseases outpatient department of a rural tertiary care hospital
}

\author{
Preety Bansal*, Seema Baishnab
}

Department of Pharmacology, Maharaja Agrasen Medical College, Agroha, Haryana, India

Received: 23 January 2020

Accepted: 28 February 2020

*Correspondence:

Dr. Preety Bansal,

Email: preetybansal137@gmail.com

Copyright: ( $)$ the author(s), publisher and licensee Medip Academy. This is an open-access article distributed under the terms of the Creative Commons Attribution Non-Commercial License, which permits unrestricted non-commercial use, distribution, and reproduction in any medium, provided the original work is properly cited.

\section{ABSTRACT}

Background: Fungal infections of the skin were the $4^{\text {th }}$ most common skin disease in 2010 affecting 984 million people. An estimated $20-25 \%$ of the world's population has some form of fungal infection. Dermatophytes are fungi that cause superficial infections of the skin, commonly referred to as tinea infections.

Methods: This was a prospective and an observational study conducted from February 2018 to January 2019 in Dermatology Department. Prescriptions included all newly diagnosed patients with cutaneous fungal infection of both sex who attended dermatology OPD. Factors considered were sociodemographic parameters, the disease encountered and number of patients in each group and number of patients who received antifungal therapy (oral and topical) etc.

Results: 1000 prescriptions were analysed of patients between 18 to 65 years of age with cutaneous fungal infections. There were a greater number of males $(57.4 \%)$ than females $(42.6 \%)$. The average number of antifungal drugs prescribed per prescription was 2.33 . Majority of the patients were prescribed itraconazole $(82.30 \%)$ followed by terbinafine $(9.70 \%)$ and fluconazole $(8.0 \%)$.

Conclusions: The most common oral antifungal drug used was itraconazole. Ketoconazole and Terbinafine were the most commonly used topical agents respectively.

Keywords: Fungal infections, Itraconazole, Ketoconazole, Tinea cruris

\section{INTRODUCTION}

An estimated $20-25 \%$ of the world's population has some form of fungal infection, usually an Anthrophillic tricophyton infection, making fungal infections the most common type of infection worldwide. ${ }^{1}$ Fungal infections of the skin were the 4th most common skin disease in 2010 affecting 984 million people. ${ }^{2}$ It is more prevalent in tropical and subtropical countries like India where the heat and humidity is high for most part of the year. There are several reports on intracontinental variability of the global incidence because of the change in climatic condition across the world. ${ }^{3}$ Fungal infections constitute a serious threat to human health and life. ${ }^{4}$ Dermatophytes are fungi that cause superficial infections of the skin, commonly referred to as tinea infections. Transmission of these infections can be via person to person spread, by soil contact or from animal contact. Fungal infections of the scalp are referred to as Tinea capitis; Tinea pedis is a superficial fungal infection of the foot; groin infections are referred to as Tinea cruris; and most other superficial skin infections due to tinea are categorised as Tinea corporis. $^{5}$

Antifungal therapy has undergone a tremendous transformation in recent years. ${ }^{6}$ The current therapeutics agents can be broadly classified into two groups: first, the naturally occurring antifungal antibiotics such as the polyenes and echinocandins, and second, synthetic drugs including azoles and fluorinated pyrimidines. ${ }^{7}$ The azoles 
antifungals include two broad classes, imidazoles and triazoles. Imidazoles are clotrimazole, miconazole, ketoconazole, econazole, sertaconazole, luliconazole, tioconazole, oxiconazole. Triazoles are itraconazole, fluconazole, voriconazole and posaconazole. The major effect of imidazoles and triazoles on fungi inhibition of $14 \alpha$-sterol demethylase, a CYP and the product of the gene ERG11 and thus impair ergosterol synthesis leading to cascade of abnormalities in the fungus. ${ }^{8,9}$

As there are few reports in the Indian context regarding the Pharmacoepidemiology of local fungal infections, the present prospective observational study was conducted to assess the pattern of antifungal drugs use in the management of local fungal infections in a tertiary care teaching hospital.

\section{METHODS}

\section{Study design}

This was prospective and an observational study conducted in the Dermatology outpatient department of Maharaja Agrasen Medical College Hospital and Research Centre for 1 year (February 2018 to January 2019) after getting approval from the Institutional ethical committee.

\section{Sample selection}

Patients were selected on the basis of our inclusion and exclusion criteria which were as follows

\section{Inclusion criteria}

Patients between 18-65 years of either sex who visit skin and venereal disease department for the first time and were prescribed antifungal drugs. Prescriptions with antifungal drugs for local fungal infection. Patient who were ready to give written informed consent.

\section{Exclusion criteria}

Those OPD patients who were admitted in wards of Skin and VD department/referred patients to dermatology department by other departments. Patients below 18 years and above 65 years. Prescriptions without antifungal drugs. Patients who were not ready to give written informed consent.

\section{Data collection}

All necessary and relevant patient information and drugs prescribed were collected from patient's prescription. The data were filled in the case record proforma.

Factors analysed were demographic parameters (age and sex), the disease encountered and number of patients in each group, number of patients who received antifungal therapy (oral and topical), number of antifungal drugs prescribed from different antifungal group and number of antifungal drugs prescribed per prescription

\section{Statistical methods}

The data obtained from the prescription were sorted and analyzed for demographic characteristics and drug use pattern. All the data were compiled into Microsoft Office Excel 2010 version and a descriptive statistical analysis was carried out. The results on continuous measurement scale were presented as mean $\pm \mathrm{SD}$ and results on categorical measurement type were presented as simple percentage. Epi info 0.7 software was used for analysis.

\section{RESULTS}

During this study a total of 1000 prescriptions of antifungal drugs were analysed for local fungal infections in between 18 to 65 years of age. Analysis of 1000 prescription showed, a total of 2331 antifungal drugs were prescribed. The average number of antifungal drugs prescribed per prescription was 2.33 .

\section{Age wise distribution}

A total of 1000 patients' prescriptions were analysed according to inclusion criteria between 18 to 65 years of age. These patients divided into the five groups according to their age. Majority of the patients were from 18 to 27 years of age $(47.4 \%)$ followed by $28-37$ years age group $(23.7 \%)$. Less common age group affected were between 48-57 years $(7.3 \%)$ and 58-65 years age group (5\%) as shown in Figure 1.

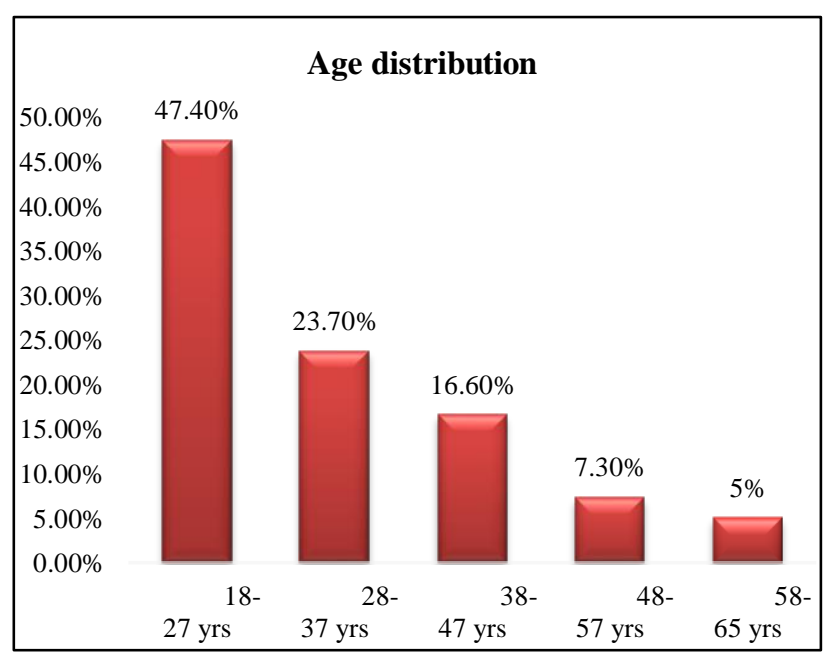

Figure 1: Age wise distribution.

Mean age was found to be $31.78 \pm 11.88$ years.

\section{Sex wise distribution}

Out of 1000 participants, 574 were male and 426 were female affected with fungal infections. The male to female ratio was 1.34, shown in Figure 2. 


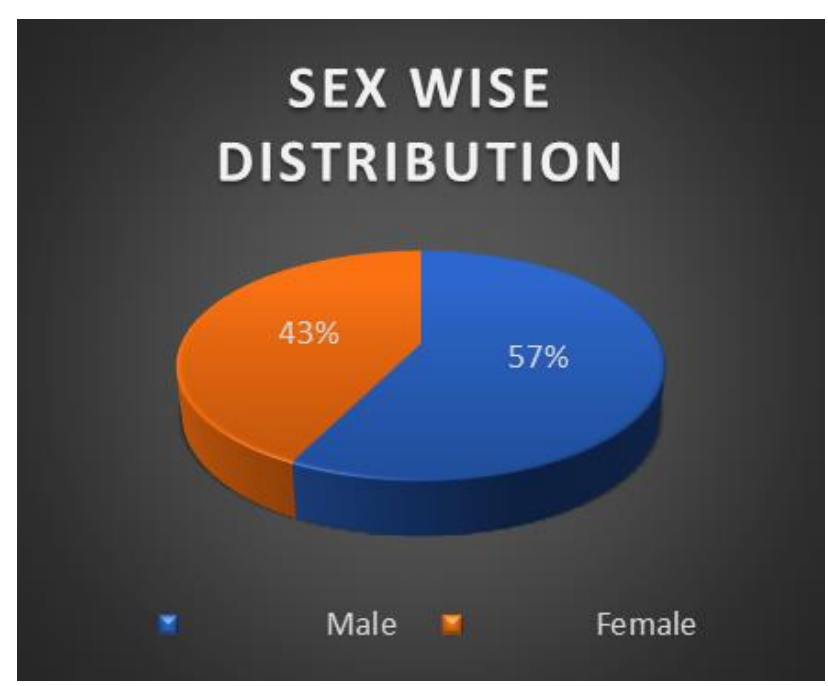

Figure 2: Sex wise distribution.

\section{Disease distribution}

Different type of fungal diseases were diagnosed in the study participants. Diseases were divided into the groups and number of patients affected with them were ruled out. Table 1 shows most common infection in study population was Tinea cruris $(41.5 \%)$ followed by Tinea corporis $(38.20 \%)$. Tinea faciei (5.30\%), Tinea incognito (3.90\%), Candidal intertrigo (3.70\%), Pityriasis versicolor $(2.80 \%)$ and Onychomycosis $(2.50 \%)$ were less commonly seen in study participants.

Table 1: Distribution of the fungal infections among the study participants.

\begin{tabular}{|l|l|l|}
\hline Disease & $\begin{array}{l}\text { Total number } \\
\text { of patient }\end{array}$ & Percentage \\
\hline Tinea corporis & 382 & 38.20 \\
\hline Tinea cruris & 415 & 41.50 \\
\hline Candidal intertrigo & 37 & 3.70 \\
\hline Tinea incognito & 39 & 3.90 \\
\hline Tinea faciei & 53 & 5.30 \\
\hline Tinea pedis & 9 & 0.90 \\
\hline Tinea mannum & 12 & 1.20 \\
\hline Pityriasis versicolor & 28 & 2.80 \\
\hline Onychomycosis & 25 & 2.50 \\
\hline Total & 1000 & 100 \\
\hline
\end{tabular}

\section{Occupation distribution}

In this study prescriptions were divided according to different occupations like farmers, students, homemakers, labourers and others (include teachers, businessman's, drivers, photographers and shopkeepers). Table 2 shows homemakers $(30.20 \%)$ were most commonly affected with the superficial fungal infection followed by students $(24.50 \%)$ and farmers $(21.10 \%)$. Labourers $(9.70 \%)$ and others $(14.50 \%)$ were less commonly affected.
Table 2: Distribution of the occupations among the study participants.

\begin{tabular}{|lll|}
\hline Occupation & Total number of patients & Percentage \\
\hline Farmer & 211 & 21.10 \\
\hline Student & 245 & 24.50 \\
\hline Homemaker & 302 & 30.20 \\
\hline Labourer & 97 & 9.70 \\
\hline Others & 145 & 14.50 \\
\hline Total & 1000 & 100 \\
\hline
\end{tabular}

\section{Prescription analysis}

In this study three different types of oral antifungal drugs were prescribed in 1000 participants which were itraconazole, terbinafine and fluconazole. Each prescription contain one oral antifungal drug and other drugs. A total of 2331 antifungal drugs were prescribed in 1000 prescriptions, out of which 1000 were oral antifungal drug. The utilization of these drugs were seen among the study participants. Table 3 shows majority of the patient were prescribed itraconazole $(82.30 \%)$ followed by terbinafine $(9.70 \%)$ and fluconazole $(8.0 \%)$.

Table 3: Utilization of oral antifungal drug.

\begin{tabular}{|lll|}
\hline \multicolumn{1}{|c}{ Drug } & Total number of drugs & Percentage \\
\hline Itraconazole & 823 & 82.30 \\
\hline Terbinafine & 97 & 9.70 \\
\hline Fluconazole & 80 & 8.0 \\
\hline Total & 1000 & 100 \\
\hline
\end{tabular}

Six different types of topical antifungal drugs were prescribed to the study participants which were ketoconazole, terbinafine, eberconazole, luliconazole, sertaconazole and amorolfine. Table 4 shows most commonly topical (cream) drug prescribed was ketoconazole $(31.10 \%)$ followed by terbinafine $(30.20 \%)$ and Sertaconazole (12.70\%).

Table 4: Distribution of the topical (creams) antifungal drugs.

\begin{tabular}{|lll|}
\hline Drug & Total number of drugs & Percentage \\
\hline Ketoconazole & 311 & 31.10 \\
\hline Terbinafine & 302 & 30.20 \\
\hline Eberconazole & 87 & 8.70 \\
\hline Luliconazole & 97 & 9.70 \\
\hline Sertaconazole & 127 & 12.70 \\
\hline Amorolfine & 76 & 7.60 \\
\hline Total & 1000 & 100 \\
\hline
\end{tabular}

Antifungal soaps and powders were also prescribed along with oral and topical antifungal drugs in few prescriptions. Out of 2331 antifungal drugs, prescribed 331 antifungal drugs were soaps and powders. 


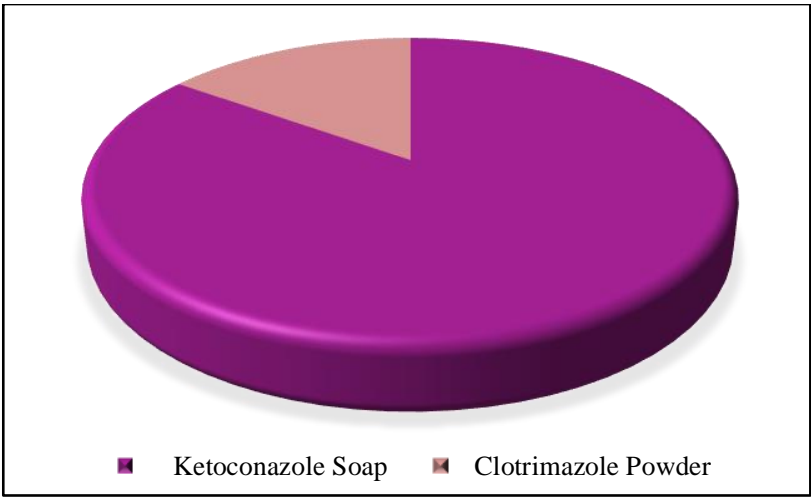

Figure 3: Utilization of antifungal soaps and powders.

Figure 3 shows $84.90 \%$ were ketoconazole $(n=281)$ soaps and $15.10 \%$ were clotrimazole powders $(n=50)$ prescribed.

\section{DISCUSSION}

In the present study, $57.40 \%$ of the study subject were male and $42.60 \%$ were female which shows male preponderance. In a study done by Patil et al showed male were affected $56.86 \%$ followed by the female $43.14 \% .^{10}$ In George et al study also most commonly male $(51.35 \%)$ were affected followed by female. ${ }^{11}$

Dermatophytosis can affect every age group with no specific age group being immune to the infection. In present series, the age of the affected patients ranged from 18 years to 65 years. Although all age groups can be affected, the majority of patients in our study were in the 18 to 27 years age group accounting for $47.4 \%$ of the patients. This age group was closely followed by $28-37$ years accounting for $23.7 \%$ of the patients. In a study done by Jain et al and Shukla et al they observed that the most common affected age group was 21-30 years of age which is similar with our study. ${ }^{12,13}$

In this study prescriptions were divided according to different occupations like farmers, students, homemakers, labourers and others (include teachers, businessmen, drivers, photographers and shop keepers). Present study showed that homemakers $(30.20 \%)$ most commonly affected followed by students $(24.50 \%)$ and farmers $(21.10 \%)$. Vegda et al conducted study in a tertiary care hospital showed mostly homemakers were affected. ${ }^{14}$ In Andrea et al, the maximum number of patients belong the group of homemakers. This was followed by students. ${ }^{15}$ In present study others group include businessman, serviceman, teachers, photographers, drivers which were least affected. In Vegda et al study the least group affected was serviceman and buisnessman. ${ }^{14}$

Superficial fungal infections are classified according to their anatomic area of involvement. In our study different types of fungal infections were diagnosed in the patients. Among them Tinea cruris was the commonest and seen in $41.50 \%$ of the patients followed by Tinea corporis which was seen in $38.20 \%$ of the patients. Khosley et al also reported the similar observation in his study as Tinea cruris $(55.07 \%)$ followed by Tinea corporis $(39.20 \%)$ as the most common clinical pattern. ${ }^{16}$

Systemic antifungal agents such as terbinafine, ketoconazole, fluconazole, griseofulvin and itraconazole have been known to be active against dermatophytes, terbinafine being the only fungicidal drug. Among these drugs, itraconazole and terbinafine are more often prescribed compared to griseofulvin and fluconazole, probably because the latter require longer duration of treatment. ${ }^{17}$

In present study majority of the patient were prescribed itraconazole $(82.30 \%)$ followed by terbinafine $(9.70 \%)$. In George et al most commonly systemic antifungal drug prescribed was itraconazole. ${ }^{11}$

Topical antifungal agents provide high concentration of the drug at the site of action and hence are preferred to be used along with the systemic antifungal drugs. ${ }^{17}$

In present study six different types of topical antifungal agents were prescribed along with the oral antifungal drugs. These were ketoconazole $(31.10 \%)$, terbinafine $(30.20 \%)$, sertaconazole $(12.70 \%)$, luliconazole $(9.70 \%)$, eberconazole $(8.70 \%)$ and amorolfine $(1.60 \%)$.

Among them ketoconazole (31.10\%) and terbinafine (30.20\%) most commonly prescribed followed by Sertaconazole $(12.70 \%)$. This is in contrast with the Kaur et al in which ketoconazole was most commonly prescribed. ${ }^{18}$ In Gopimohan et al most commonly prescribed topical agent was terbinafine. ${ }^{19}$

Antifungal soaps and powders were also prescribed along with oral and topical antifungal drugs in few prescriptions. Out of 2331 antifungal drugs, prescribed 331 antifungal drugs were soaps and powders. $84.90 \%$ were Ketoconazole $(n=281)$ soaps and $15.10 \%$ were clotrimazole powders $(n=50)$ prescribed. In Pathak et al study among topical agents clotrimazole, ketoconazole were used in form of powder, shampoo and soaps. ${ }^{20}$ Kumar et al study showed ketoconazole soap and clotrimazole powder were commonly used. ${ }^{21}$

\section{CONCLUSION}

In present study Tinea cruris is most common fungal infection affecting 18 to 27 years of age group. The most common prescribed oral antifungal drug is itraconazole. Ketoconazole and terbinafine are the most commonly prescribed topical agents respectively.

\section{ACKNOWLEDGEMENTS}

Author is thankful to Dr. Seema Baishnab, Professor and Head, Dept. of Pharmacology, Maharaja Agrasen Medical 
College, Agroha (Hisar), for her valuable guidance and help to carry out this study.

Funding: No funding sources

Conflict of interest: None declared

Ethical approval: The study was approved by the Institutional Ethics Committee

\section{REFERENCES}

1. James WD, Elston DM, Berger TG. Andrew's diseases of the skin clinical dermatology. $12^{\text {th }}$ ed. Philadelphia: Elsevier; 2016:285.

2. Hay RJ, Johns NE, Williams HC, Bolliger IW, Dellavalle RP, Margolis DJ, et al. The global burden of skin disease in 2010: An analysis of the prevalence and impact of skin conditions. J Investig Dermatol. 2013;134:1527-34.

3. Lakshmanan A, Ganeshkumar P, Raam Mohan S, Hemamalini M, Madhavan R. Epidemiological and clinical pattern of dermatomycoses in rural India. Indian J Med Microbiol. 2015;33(5):134-6.

4. Al Balushi KA, Alzaabi MA, Alghafri F. Prescribing pattern of antifungal medications at atertiary care hospital in Oman. J Clin Diagn Res. 2016;10(12):FC27-30.

5. Rezabek GH, Friedman AD. Superficial fungal infections of the skin diagnosis and current treatment recommendations. Drugs. 1992;43(5):674-82.

6. Murray PR, Rosenthal KS, Pfaller MA. Medical microbiology. 7th ed. Philadelphia: Elsevier; 2013: 631.

7. Rang HP, Ritter JM, Flower RJ, Henderson G. Rang \& dale's pharmacology. 8th ed. Elsevier; 2012:654.

8. Rogers PD, Krysan DJ. Antifungal agents. In: Brunton LL, Dandan RH, Knollmann BC, eds. Goodman and Gillman's the pharmacological basis of therapeutics thirteenth edition. New York: McGraw-Hill; 2018: 1091.

9. Tripathi KD. Essentials of medical pharmacology. 7th ed. New Delhi: Jaypee Publication; 2013:790-1.

10. Patil A, Dighe D, Kolte S, Jadhav PR, Deshmukh YA. Drug utilization pattern in dermatology outpatient department at a tertiary care hospital in Navi Mumbai. Int J Basic Clin Pharmacol. 2017;6(3):559-62.

11. George AJ, Godbole D, Mali M, Pawar S. Assessment of etiology pattern and treatment of tinea infections in a tertiary care hospital. Advanc Med Dental Health Sci. 2018;1(1):8-11.
12. Jain N, Sharma M, Sharma M, Saxena VM. Spectrum of dermatophytosis in Jaipur. Afr J Microbiol. 2014;8(3):237-43.

13. Shukla P, Yaqoor S, Shukla V, Garg J, Dar ZP, Haider F. Prevalence of superficial mycosis among outdoor patients in a tertiary care hospital. Nat J Med Sci. 2013;2(2):19-26.

14. Vegada BN, Karelia BN, Singh AP. Drug utilization study of antifungal agents used in department of skin and V.D. of a tertiary care teaching hospital. Int J Pharm Sci Rev Res. 2015;34(1):118-21.

15. Andrea C, Pires A, Lobato AM, Regina F, Carneiro O. Clinical, epidemiological, and therapeutic profile of dermatophytosis. An Bras Dermatol. 2014;89(2):259 -65.

16. Koshley V, Halwai AK, Koshley SB, Kurrey PK, Jaiswal S. Treatment pattern of dermatophytosis at the outpatient clinic of a tertiary healthcare hospital of Chhattisgarh, central India. Indian J Clin Exp Dermatol. 2018;4(4):327-30.

17. Rengasamy M, Chellam J, Ganapati S. Systemic therapy of dermatophytosis: practical and systematic approach. Clin Dermatol Rev. 2017;1:S19-23.

18. Kaur M, Sumir Kumar S, Singh P. A cost analysis study on drug prescribing pattern of antifungal in dermatological conditions at tertiary care teaching hospital, Punjab. Eur J Pharm Med Res. 2017;4(4):461-4.

19. Gopimohan P, Sudha MJ, Pillai RT, Ramani PT. A study on the prescription pattern of antifungal drugs in the dermatology department of a tertiary care teaching hospital in southern Kerala. Int J Basic Clin Pharmacol. 2019;8(1):100-103.

20. Pathak AK, Kumar S, Kumar M, Mohan L, Dikshit H. Study of drug utilization pattern for skin diseases in dermatology opd of an Indian tertiary care hospital- a prescription survey. J Clin Diagn Res. 2016;10(2):FC0105.

21. Kumar J, Chandra S, Sinha HK. Utilization pattern of drugs among dermatological outpatients in a tertiary care hospital of eastern India. Int J Clin Pharmacol Res. 2016;6(9):297-302.

Cite this article as: Bansal $\mathrm{P}$, Baishnab S. A pharmacoepidemiology study of local fungal infections in skin and venereal diseases outpatient department of a rural tertiary care hospital. Int $\mathbf{J}$ Basic Clin Pharmacol 2020;9:616-20. 